\title{
ICG Fluorescence Technique for the Detection of Sentinel Lymph Nodes in Breast Cancer: Results of a Prospective Open-label Clinical Trial
}

\author{
Sentinel-Lymphknoten-Detektion beim Mammakarzinom mittels \\ Fluoreszenztechnik - eine Alternative zum Technetiumverfahren?
}

Authors

Affiliation
E.-M. Grischke, C. Röhm, M. Hahn, G. Helms, S. Brucker, D. Wallwiener

Universitäts-Frauenklinik Tübingen, Tübingen

\section{Key words \\ - breast cancer \\ - breast \\ - gynecology \\ - epidemiology \\ Schlüsselwörter \\ - Mammakarzinom \\ - Mamma \\ - Gynäkologie \\ - Epidemiologie}

Deutsche Version unter: www.thieme-connect.de/ ejournals/gebfra

\section{received 11.2.2014 \\ revised 25.6.2015 \\ accepted 25.6.2015}

\section{Bibliography}

DOI http://dx.doi.org/

10.1055/s-0035-1557905

Geburtsh Frauenheilk 2015; 75:

935-940 ๑ Georg Thieme

Verlag KG Stuttgart · New York . ISSN 0016-5751

\section{Correspondence}

\section{Prof. Dr. Eva-Maria Grischke}

Universitäts-Frauenklinik

Calwerstraße 7

72076 Tübingen

Eva-Maria.Grischke@

med.uni-tuebingen.de

\section{Abstract}

\section{$\nabla$}

Introduction: Detection of sentinel lymph nodes (SLN) is the standard procedure to evaluate axillary lymph node status in breast cancer. In addition to known and established procedures such as the blue dye method and scintigraphy, this study investigated the efficacy of a method based on use of the fluorescent dye indocyanine green (ICG).

Patients and Method: A total of 126 women with breast cancer histologically verified by punch biopsy were studied during surgical removal of SLN. In addition to SLN marking with technetium and scintigraphy, intra-individual comparison was done using indocyanine green (ICG) for marking instead of the standard blue dye.

Results: Scintigraphy had a detection rate of $96 \%$; the detection rate with ICG was just under $89 \%$. A body mass index $(\mathrm{BMI})>40$ was found to be a limiting factor for the fluorescent method. Investigation into potential toxicities associated with the use of the fluorescent dye ICG revealed no systemic or even local side effects. The fluorescent method was found to be significantly less expensive than the scintigraphy method.

Conclusion: The ICG fluorescence technique for the detection of SLN was found to be a valid and feasible method in clinical practice when compared directly with the blue dye method and scintigraphy.

\section{Zusammenfassung \\ $\nabla$}

Einleitung: Die Detektion des Sentinel-Lymphknotens (SLN) ist mittlerweile ein Standardverfahren zur Erfassung des axillären Lymphknotenstatus beim Mammakarzinom. Neben den bekannten und etablierten Verfahren, wie der blauen Farbstoffmethode und dem szintigrafischen Verfahren, wurde in der vorliegenden Untersuchung die Aussagefähigkeit einer Methode überprüft, basierend auf dem Einsatz eines Fluoreszenzfarbstoffs in Form von Indocyaningrün (ICG).

Patientinnen und Methoden: Untersucht wurden dabei insges. 126 Patientinnen mit durch Stanzbiopsie histologisch gesichertem Mammakarzinom im Rahmen der operativen Entfernung des SLN. Neben einer standardmäßigen szintigrafischen Markierung des SLN mittels Technetium erfolgte im intraindividuellen Vergleich anstelle der üblichen Blaumarkierung die Markierung mittels Indocyaningrün (ICG).

Ergebnisse: Es konnte mit der Szintigrafie eine Detektionsrate von 96\% erreicht werden, mittels ICG eine Rate von knapp 89\%. Als limitierender Faktor für das Fluoreszenzverfahren erwies sich ein Body-Mass-Index > 40 (BMI > 40). Die Erfassung von möglicherweise auftretenden Toxizitäten bei Anwendung des Fluoreszenzfarbstoffs ICG ergab keinen Hinweis auf systemische oder auch lokale Nebenwirkungen. Im Kostenvergleich erweist sich die Fluoreszenztechnik als deutlich kostengünstiger als das szintigrafische Verfahren. Schlussfolgerung: Die SLN-Detektion mittels Fluoreszenzverfahren durch Einsatz von ICG erweist sich im klinischen Einsatz und direktem Vergleich zur blauen Farbstoffmethode und dem szintigrafischen Verfahren als valides und praktikables Verfahren. 


\section{Introduction}

The diagnosis and treatment of early-stage breast cancer has improved significantly in the last few decades through the use of better diagnostic methods (including mammogram screening) as well as a better understanding of tumor biology in terms of gene signatures and risk prediction models [1-4]. Reducing the extent of radical surgery in the axilla was another important step. Axillary lymph node status continues to be one of the most important prognostic factors [5-7]. This means that histopathological assessment of node status is still an integral part of the surgical treatment of invasive breast cancer. The introduction of sentinel lymph node biopsy (SLNB) was a first step on the way to reducing the extent of radical surgery and the secondary morbidity associated with axillary lymph node dissection such as pain, impaired sensitivity and lymph edema.

The SLNB method already existed and was primarily used to treat tumor entities such as malignant melanoma, prostate cancer, gastrointestinal tumors and bronchial carcinoma. Scintigraphy combined with the radionuclide technetium-99m was the first method generally used to mark SLN. Scintigraphy has a learning curve but detection rates with scintigraphy are now well over $90 \%$, with a sensitivity of $91.2 \%$ and a false negative rate of $8.8 \%$ [9]. The literature reports detection rates between $86 \%$ (sensitivity $89 \%$, false negative rate of $9.1 \%$ ) and $96.2 \%$ (false negative rate $3.7 \%$ ). Detection rates have improved as the technique has been optimized, intensifying the learning curve [10-13]. In the wake of the technetium method, a number of other methods including marking with blue dye were quickly developed and established in clinical practice. The combination of both methods has low false negative rates of just $5-10 \%$ and higher detection rates. In the literature there are reports of detection rates of $100 \%$ for scintigraphy and $92.9 \%$ for Patent blue dye marking [14]. As scintigraphy is associated with not inconsiderable costs, not least because of the requirement of a clinic or department of nuclear medicine, this has meant that certain centers, particularly in England, only perform marking with blue dye or assisted limited axillary lymph node dissection after blue dye marking $[15,16]$. The often limited availability of the radionuclide has also encouraged the trialing and use of other new detection methods. This has resulted in the development of a fluorescent method using the fluorescent dye indocyanine green (ICG) [17]. In addition to studies on its use in the treatment of breast cancer, there are a number of other reports on its use to treat malignant melanoma, or more generally in dermatosurgery, small cell lung cancer, and gastrointestinal tumors.

Studies have shown that ICG fluorescence imaging alone or in combination with the blue dye method or the radionuclide method is a safe and easy technique. Detection rates range from $100 \%$ for technetium, $92.9 \%$ for the blue dye method and $99.3 \%$ for ICG [14]. A direct comparison between the two dye methods found that ICG was more sensitive, with a reported sensitivity of $99 \%$, compared to the blue dye method which had a sensitivity of $78 \%$ [18].

This study aimed to investigate the efficacy of the ICG fluorescence technique and compare it to the use of technetium in a prospective study which simultaneously aimed to record potential systemic or local toxicities. The decision was taken not to use any other dye, in this case, not to use the blue dye method, to avoid possible interactions between the two dye methods.

\section{Material and Method}

$\nabla$

\section{Study design}

A total of 126 patients were investigated in a non-randomized single-center phase II trial. SLN detection was done using conventional technetium marking as well as fluorescence detection using intradermal injection of the ICG dye done in parallel for intra-individual comparison. The numbers of lymph nodes detected with the two methods were recorded and compared for individual patients as were the total number of SLNs detected using the two different methods. To assess how well ICG was tolerated, core data such as BMI and biosafety as well as potential reactions such as permanent skin marking were recorded.

\section{Technetium marking and fluorescence imaging}

Patients with breast cancer verified by punch biopsy who met the inclusion and exclusion criteria for SLNB were included in the study. Indications for SLNB were based on the relevant guideline currently valid in Germany [7]. Patients received 99 mTC Nanocoll ${ }^{\circledR}$ and indocyanine green (ICG, obtained from Pulsion) for SLN detection. The commercially available Nanocoll ${ }^{\circledR}$ kit (human albumin $500 \mu / \mathrm{vial}$; GE Healthcare) was used for technetium marking. Nanocoll ${ }^{\circledR}$ was reconstituted with sodium pertechnetate (99 mTC) to prepare the technetium-99m albumin nanocolloid injection solution. The administered 99 mTC Nanocoll solution was injected subcutaneously in the perialeolar region according to protocol. The analogue was administered in a dose of 39-102 Mbq according to standard clinical practice.

The preparation was administered on the afternoon of the day preceding surgery or on the day of surgery itself. If a two-day protocol was followed, the standard injected dose was 50$80 \mathrm{MBq} \mathrm{TC}$; the standard dose administered to patients treated according to the one-day protocol was $20-40 \mathrm{Mbq}$ TC.

ICG Pulsion was prepared immediately prior to surgery. A vial containing $25 \mathrm{mg}$ indocyanine green (trial medication) was prepared with $5 \mathrm{ml}$ distilled water. Immediately preoperatively patients received an intradermal injection of $2 \mathrm{ml}$ of the ICG solution $(10 \mathrm{mg})$ administered in the periareolar region to the breast quadrant in which the tumor resided. This was followed by a $10-$ 15 minute massage until the start of fluorescence detection. A special charge-coupled camera with light-emitting diodes that generate light at a wavelength of $760 \mathrm{~nm}$ and which simultaneously registers the fluorescence signal was used. The CCD camera filters light with a wavelength of less than $820 \mathrm{~nm}$. Fluorescence signals were continuously displayed in real-time as black and white images [19].

In the clinical trial, lymph drainage pathways were followed from the site of injection to the axilla ( Fig. 1). Sentinel lymph nodes were assumed to be present when lymph drainage pathways ceased, indicating penetration of the fluorescent dye into deeper subcutaneous tissue layers. The skin was marked at these sites using conventional marking techniques. Fluorescence penetrates human tissue to a depth of $1.5-2 \mathrm{~cm}$, meaning that with this approach fluorescence can be detected at a maximum of depth of $2 \mathrm{~cm}$. A fluorescent lymph node was detected in most patients ( Fig. 2). Conventional detection of SLN marked in advance with technetium was done immediately after fluorescence imaging. Radioactivity of the SLN or group of nodes detected by fluorescence was routinely checked. Counts per second (CPS) were determined at the gamma probe of the Neoprobe gamma detection system, with TC activity indicated by conversion of CPS to MBq. 

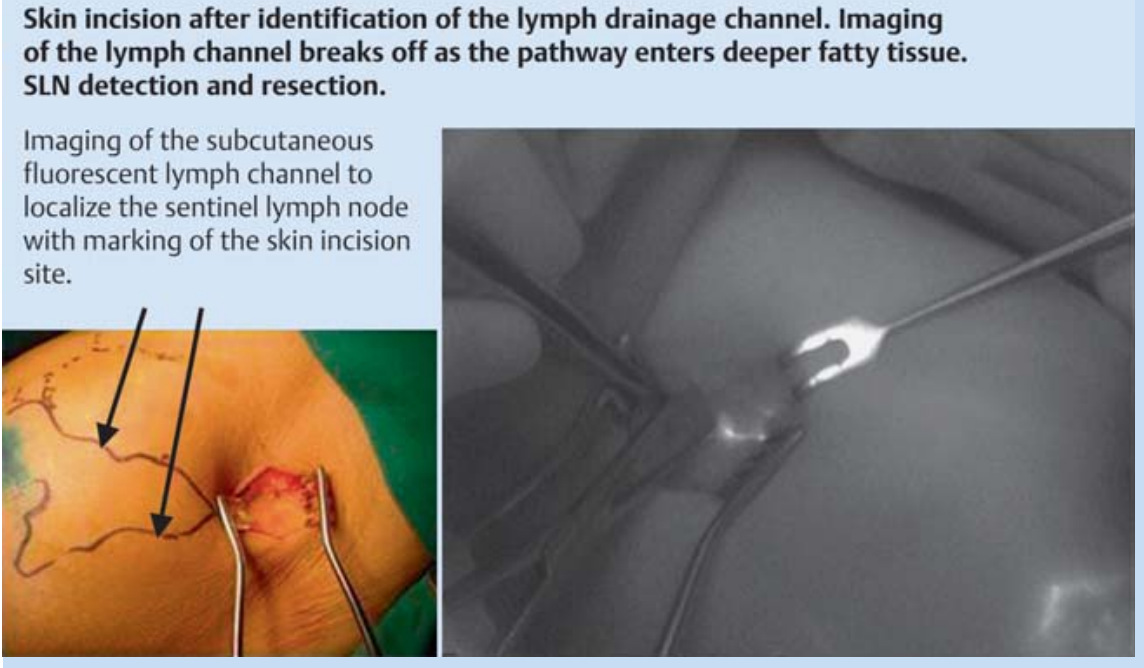

Fig. 1 Use of ICG in clinical practice for the detection and resection of sentinel lymph nodes. Skin incision after identification of the lymph drainage pathway; fluorescence imaging ceases as the dye penetrates deeper into the fatty tissue; SLN detection and resection. Imaging of the subcutaneous fluorescent lymph drainage channel with marking of the skin incision site to locate the sentinel lymph node.

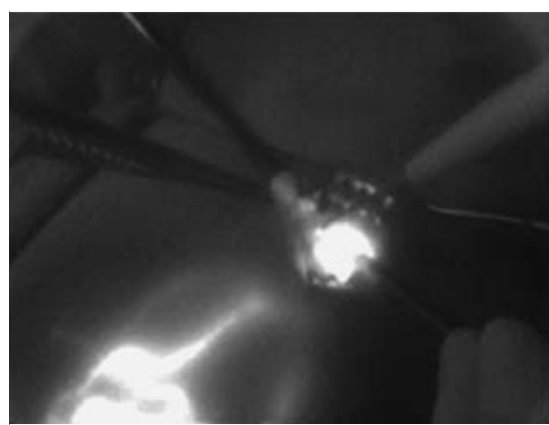

Fig. 2 Lymph drainage pathway and fluorescent sentinel lymph node.
The lymph node was then resected after renewed examination and recording of fluorescence ( $\bullet$ Fig. 3 ).

Subsequently, both methods were reviewed according to standard clinical practice in terms of additional detectable lymph nodes. If more signals or fluorescence were detected, additional lymph nodes were also resected.

\section{Data collection and analysis}

Histopathologic examination of individual marked and resected SLNs was done separately and results were recorded. The method used to detect the SLN was recorded. There were only a few cases where the two detection methods differed with respect to individual lymph node groups.

In the overall assessment, detection using the two methods was recorded for each individual patient or axilla, not according to individual SLNs.

To compare our results with those of the literature the total number of lymph nodes detected with the respective methods was also recorded.

\section{Toxicity}

As this was a phase II trial, patient tolerance of the fluorescent dye ICG obtained from Pulsion and all potential side effects were recorded. Organ toxicity and local toxicity after intradermal injection were assessed. ICG has been approved for intravenous administration. In this study ICG was administered by intradermal injection rather than by the standard intravenous route. Routine laboratory tests were performed after intradermal ICG administration together with local examination of the injection site. Par-

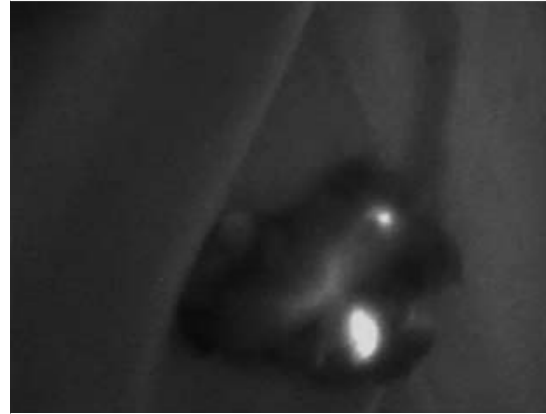

Fig. 3 Resected fatty tissue with lymph nodes and lymphatic drainage shown using only the fluorescence method.

ticular attention was paid to any discoloration of the skin or tattooing, and all skin reactions including reddening or swelling were recorded.

\section{Results \\ $\nabla$}

\section{Patient characteristics and tumor stage}

A total of 126 patients were recruited into the study. In 17 patients, the fluorescent dye was not administered according to study protocol. These patients were subsequently excluded from analysis. Another 4 patients with suspicion of tumor involvement of the axillary lymph nodes based on imaging and palpation had no indication for SLN biopsy. The data of 105 patients were ultimately included in the analysis. Five patients had bilateral cancer. The mean patient age was 57.5 years; 5 patients were older than 80 years $(81,82$ and $3 \times 84$ years $)$. The most common tumor stage in the overall patient population was pT2 in 43 cases, followed by tumor stage pT1c in 42 cases. Three patients had tumor stage pT1a, and 21 patients had tumor stage pT1b. A total of 17 patients had either extensive pTis or pTmic. G 1 grade was present in $23 \%$ of patients, G 2 in $45 \%$ and G 3 in $32 \%$.

The mean BMI was $26 \pm 5.32$. Three patients had a BMI $>40$.

\section{Detection of lymph nodes}

Intra-individual comparison of lymph node detection using technetium and ICG

Of 105 patients whose data were available for analysis, SLN detection using technetium was achieved in 104 cases, which corre- 
sponds to a detection rate of $98 \%$. When ICG was used, SLN detection was achieved in 93 patients, which corresponds to a detection rate of $89 \%$. SLN detection with ICG and technetium was achieved in 91 of 105 patients. SLN were identified using ICG but not technetium in 2 of 105 patients; SLN were identified using technetium but not ICG in 12 of 100 patients ( Table 1). Using both methods, a total of 162 SLN were identified and resected. A total of 157 SLN were detected using technetium (96\%), while 138 SLN (85\%) were identified using ICG. Overall, $96 \%$ of SLN were identified using technetium ( Table 2 ).

Two of the patients in the group where SLN were detected using technetium but could not be identified with ICG had a BMI of $>40$ (BMI 40.4 and 40.9, respectively). The time from injection of the ICG fluorescent dye to the start of SLN detection was at least 10 minutes; the maximum time from injection to detection was 25 minutes in accordance with the study protocol and the approach used for breast surgery. The time from the start of detection to SLN excision was 8-10 minutes.

\section{SLN detection using both methods irrespective of tumor involvement}

In 91 patients SLN were detected using both ICG and technetium, with SLN subsequently resected and investigated for tumor involvement. In the group of patients in whom SLN were detected using technetium but not identified with ICG, 2 patients were found to have tumor involvement. In the group in whom SLN were detected with both technetium and ICG, histological investigation identified tumor involvement of the SLN in 25 patients ( Table 3). In the group of patients in whom SLN could not be identified with either of the methods, the histological results were reviewed. No correlation was found between non-detection of lymph nodes and histopathological evidence of lymph node involvement.

\section{Influence of other variables on fluorescence detection Importance of body mass index (BMI)}

The detection rate with ICG in patients with a BMI of less than 40 (<40 BMI) was $89 \%$. There was no difference in detection rate when a cut-off of BMI $<30$ or 35 was used. Detection with ICG was only difficult in patients with BMI $>40$. No SLN was detected using the fluorescence method in 2 of 3 patients with a BMI $>40$. This could be explained by the fact that the fluorescence method is only considered adequate at a maximum penetration depth of $2 \mathrm{~cm}$.

\section{Pharmaceutical drug safety}

Systemic and local toxicity

To investigate the pharmacological safety of the fluorescent dye used, all side effects occurring subsequent to the administration
Table 1 SLN detection with TC and fluorescence technique in 105 patients.

$\begin{array}{ll}\text { - Detected with TC } & \mathrm{n}=103(98 \%) \\ \text { - Detected with ICG } & \mathrm{n}=93(89 \%) \\ \text { - SN identified using ICG and TC in } & \mathrm{n}=91 / 105 \\ \text { - SN identified with TC but not ICG in } & \mathrm{n}=2 / 105\end{array}$

Table 2 Overall numbers of SLN detected using the two methods.

\begin{tabular}{ll} 
- Total number of identified SLN & 162 \\
- Number of SLN detected with TC & $157(96 \%)$ \\
- Number of SLN detected with ICG & $138(85 \%)$ \\
- Sensitivity $(0.96 \mathrm{CI})$ & $133(82 \%)$ \\
- Positive predictive value $(0.85 \mathrm{CI})$ & $0.92-0.99$ \\
- Specificity $(0.82 \mathrm{CI})$ & $0.78-0.9$ \\
\hline
\end{tabular}

Table 3 Number of positive $\mathrm{N}+$ lymph nodes (tumor involvement) according to the method used to identify SLN.

$\begin{array}{lll}\text { - SNL detected with ICG and TC } & \mathrm{n}=91 & \mathrm{~N}+\text { in } \mathrm{n}=25 \\ \text { - SNL detected with ICG but not TC } & \mathrm{n}=2 & \mathrm{~N}+\text { in } \mathrm{n}=0 \\ \text { - SNL detected with TC but not ICG } & \mathrm{n}=12 & \mathrm{~N}+\text { in } \mathrm{n}=2\end{array}$

of ICG were recorded. Side effects were limited and of only mild to moderate severity (grade I and II) and were not related to the intradermal injection of ICG ( $\bullet$ Table 4$)$. There were no therapeutic consequences. No local skin changes such as allergic reactions or permanent skin tattoos occurred. The safety profile of ICG administered by intradermal injection did not differ from that of ICG administered intravenously.

\section{Discussion \\ $\nabla$}

SLNB is an accepted and validated standard procedure for axillary staging; it is performed during primary surgery in women with breast cancer whose SLN status is clinically and morphologically unremarkable. The most commonly used procedure for SLNB with a low false negative rate of just $9.8 \%$ consists of combining blue dye and the radionuclide technetium $99 \mathrm{~m}$ for SLN detection [8].

A number of large studies with a median follow-up time of 97 months have shown that there is no difference between the SNB

Table 4 Events which occurred during assessment of toxicity.

\begin{tabular}{|c|c|c|c|c|c|c|c|}
\hline $\begin{array}{l}\text { Screening } \\
\text { No. }\end{array}$ & Event & Ongoing & Severe & Intensity & Relationship & Actions & Outcome \\
\hline 063 & tachycardia grade 2 & 0 & no & moderate & not related & none & recovered/resolved \\
\hline 063 & vomiting grade 1 & 0 & no & mild & not related & none & recovered/resolved \\
\hline 063 & nausea grade 1 & 0 & no & mild & not related & none & recovered/resolved \\
\hline 083 & $\begin{array}{l}\text { pain during Redon suction } \\
\text { drainage }\end{array}$ & 0 & no & moderate & not related & none & recovered/resolved \\
\hline 111 & nausea & 0 & no & moderate & not related & none & recovered/resolved \\
\hline 111 & vomiting & 0 & no & mild & not related & none & recovered/resolved \\
\hline 126 & high leukocyte count (grade 2) & 1 & no & moderate & not related & none & no recovery/not resolved \\
\hline
\end{tabular}


method and complete axillary lymphadenectomy in node-negative patients with regard to the incidence of loco-regional recurrence and overall survival $[19,20]$. SNB is therefore considered a valid method in clinical practice.

The literature has shown that the blue dye method, which was not used in this study, has a lower sensitivity, which results in more lymph nodes being removed than when combined procedures are used [16]. On average, the studies report that 4-5 lymph nodes are resected compared to the combined method where only 2-3 lymph nodes are excised.

The fluorescence technique was developed during the search for other methods of SLN marking. Initially, only small patient numbers and different study designs were reported in the literature. Two studies by Hirche et al. only investigated 43 and 47 patients, respectively [21]. The fluorescence method has been used in a number of very different studies. The literature includes studies where the fluorescence dye ICG was the only method used for detection, studies where ICG was used in combination with technetium or in combination with the blue dye method or even studies which compare all three approaches. A total of 7 studies, some with larger numbers of patients (128 and 145 patients, respectively) investigated the use of ICG on its own. The comparison of the fluorescence method with the conventional technetium method is of particular interest in the context of our study.

Although the number of patients investigated in these comparative studies were relatively small, the studies found a good correlation between the fluorescence technique and the technetium method, with detection rates of $94-100 \%$ after intradermal or even subdermal administration [18,22-25].

The studies showed that the ICG fluorescence method had a high SLN detection rate and that the false negative rate was comparable with that of the technetium method [19,21,26-29]. The data of our study presented here correlate well with the detection rates reported for technetium (98\%) and for ICG (89\%) in a large patient cohort of 105 patients. A review of the literature showed not insignificant methodological differences between studies in terms of the injection technique used and the amount of administered ICG. The amount of ICG administered to patients in our study was based on previous investigations into appropriate doses, with a dose of $10 \mathrm{mg}$ ICG having been found to be safe and effective, particularly compared to a $5 \mathrm{mg}$ dose [23]. These ICG doses have also been confirmed in other studies [19,30-32]. Although there are a number of other studies, the only comparable study in terms of design and sufficient number of patients is the prospective study by Wishart et al., who investigated 100 patients [33]. With regard to the numbers of detected and resected lymph nodes, in their study the ICG detection rate was $100 \%$, while detection rate with ICG and technetium was only $77.3 \%$. In absolute numbers that means that 156 lymph nodes out of a total of 201 were detected using the radionuclide method, while all resected lymph nodes were identified using ICG fluorescence. Our figures showed that 136 out of a total of 154 lymph nodes were detected with ICG, while the number of lymph nodes detected with technetium was 147 out of 154 resected lymph nodes. The data of the two studies are clearly comparable.

Some studies investigated detection rates using both technetium and the blue dye method [33]. In addition to the above mentioned study by Wishart et al., one study also investigated larger numbers of patients ( $n=411$ patients) but they only compared ICG with the blue dye method [18]. Another larger study with 142 patients which compared ICG only with the blue dye method was a retrospective study [29].
Our study was expressly designed to compare ICG with the technetium, the current gold standard, and chose not to do an additional comparison with the blue dye method. The reason was that this study aimed to investigate prospectively whether it would be possible to forego technetium marking and use ICG for detection instead. Another consideration was that in the literature the detection rates for the blue dye method are lower compared to those for technetium. As our study also aimed to investigate the toxicity occurring after intradermal injection of ICG, our study deliberately avoided marking using the blue dye method. Studies which investigated larger numbers of patients and compared either technetium or the blue dye method with fluorescence marking have reported that the detection rates for ICG are only minimally lower compared to technetium marking. Comparative studies have demonstrated detection rates of 86 and $90 \%$, respectively [10].

Based on the results of these studies, the detection rate for ICG of $89 \%$ in individual patients compared to technetium found in our study confirms that ICG is an effective and valid method. Comparisons between studies are complicated by the use of different methods, concentrations and analyses [34].

The correlation between lymph node detection and BMI, which has only been shown in this study, showed for the first time that the efficacy of the method is significantly correlated with BMI. The cut-off was determined as a BMI $>40$. The explanation for this correlation is that imaging of lymph drainage channels using fluorescence is only possible to a maximum depth of $1.5-2 \mathrm{~cm}$. Out of the total of 12 sentinel lymph nodes not detectable by ICG, 2 cases had a BMI $>40$. In the overall patient population only 3 of 105 patients had a BMI $>40$. There were no side effects associated with intradermal ICG administration, meaning that in terms of systemic side effects there was no difference between intradermal injection and intravenous administration.

As with every approach used for SLNB, the practical application has a learning curve.

The average costs of the technetium method are between $€ 300$ 350 , while costs for the ICG fluorescence method are around $€ 100$. When, as is currently the case in most centers, technetium is combined with the blue dye method, the costs rise to $€ 450$ 500. In addition to other quality criteria which need to be considered when planning breast cancer treatment, a cost-benefit analysis is also an important quality criterion [35].

\section{Conclusion}

$\nabla$

SLN detection using the ICG fluorescence method has been shown to be a valid and effective method in clinical practice and in direct comparison with the technetium method. With a detection rate of $89 \%$ the rate for the ICG method was only slightly lower than the rate of $98 \%$ achieved with the standard technetium method.

This study is the first study to have demonstrated a correlation between SLN detection using fluorescence and patient BMI. In patients with a BMI $>40$ the method has only limited efficacy as lymph drainage channels cannot be adequately visualized. Our study found no systemic or local toxicity after intradermal injection. In terms of costs, fluorescence imaging does not require the administration of a radionuclide which is required with technetium imaging; this means that the technical complexity and the costs are lower with the ICG approach. 
The use of potential new technologies, particularly cameras with a higher resolution, is likely to lead to a higher acceptance of the method among users and even higher detection rates.

\section{Conflict of Interest}

None.

\section{References}

1 Fasching PA, Ekici AB, Wachter DL et al. Breast cancer risk - from genetics to molecular understanding of pathogenesis. Geburtsh Frauenheilk 2013; 73: 1228-1235

2 Heywang-Koebrunner S, Bock $K$, Heindel $W$ et al. Mammography screening - as of 2013. Geburtsh Frauenheilk 2013; 73: 1007-1016

3 Sinn P, Aulmann S, Wirtz R et al. Multigene assays for classification, prognosis, and prediction in breast cancer: a critical review on the background and clinical utility. Geburtsh Frauenheilk 2013; 73: 932940

4 Lux MP, Maass N, Schütz F et al. Breast cancer 2013 - interpretation of new and known data. Geburtsh Frauenheilk 2013; 73: 584-598

5 Hubalek M, Bartsch R, Gnant $M$ et al. Axillary dissection in the case of positive sentinel lymph nodes: results of the Innsbruck Consensus Conference. Geburtsh Frauenheilk 2012; 72: 293-298

6 Leitlinienprogramm Onkologie S3. Leitlinie Mammakarzinom. AWMF (Registernummer 032-045OL) Juli 2012

7 AGO Guidelines Breast Version 2014. Publiziert bei der AGO e.V.. Online: http://www.ago-online.de/en/guidelines-mamma/march-2014/

8 Lyman GH, Giuliano AE, Somerfield MR et al.; American Society of Clinical Oncology. American Society of Clinical Oncology guideline recommendations for sentinel lymph node biopsy in early-stage breast cancer. J Clin Oncol 2005; 23: 7703-7720

9 Veronesi U, Paganelli $G$ et al. A randomized comparison of sentinelnode biopsy with routine axillary dissection in breast cancer. N Engl J Med 2003; 349: 546-553

10 McMasters KM, Tuttle TM, Carlson DJ et al. Sentinel lymph node biopsy for breast cancer: a suitable alternative to routine axillary dissection in multi-institutional practice when optimal technique is used. J Clin Oncol 2000; 18: 2560-2566

11 Rubio I, Korourian S, Christopher C et al. Sentinel lymph node biopsy for staging breast cancer. Am J Surg 1998; 176: 532-537

$12 \mathrm{Krag} D$, Weaver D, Ashikaga T et al. The sentinel node in breast cancera multicenter validation study. N Engl J Med 1998; 339: 941-946

13 Rubio I, Korourian S, Christopher C et al. Sentinel lymph node biopsy for staging breast cancer. Am J Surg 1998; 76: 532-537

14 Hojo T, Nagao T, Kikuyama $M$ et al. Evaluation of sentinel node biopsy by combined fluorescent and dye method and lymph flow for breast cancer. Breast 2010; 19: 210-213

15 Purushotham AD, Macmillan RD, Wishart GC. Advances in axillary surgery for breast cancer - time for a tailored approach. Eur J Surg Oncol 2005; 31: 929-931

16 Benson JR, Querci della Rovere G. Management of the axilla in women with breast cancer. Lancet Oncol 2007; 8: 331-348

17 Motomura K, Inaji H, Komoike Y et al. Sentinel node biopsy guided by indocyanine green dye in breast cancer patients. Jap J Clin Oncol 1999; 29: 604-607

18 Sugie T, Kassim KA, Takeuchi M et al. A novel method for sentinel lymph node biopsy by indocyanine green fluorescence technique in breast cancer. Cancers (Basel) 2010; 2: 713-720
19 Abe $H$, Umeda T, Mori $M$ et al. Indocyanine green fluorescence imaging system for sentinel lymph node biopsy in early breast cancer patients. J Clin Oncol 2010; 28 (Suppl. 15): 6492

$20 \mathrm{Krag}$ DN, Anderson J, Julian TB et al. Comparison of sentinel lymph node resection to conventional axillary dissection in clinically node negative breast cancer patients: primary outcome results of NSABP B032 trial. Lancet Oncol 2010; 11: 927-933

21 Hirche C, Murawa D, Mohr Z et al. ICG fluorescence-guided sentinel node biopsy for axillary nodal staging in breast cancer. Breast Cancer Res Treat 2010; 121: 373-378

22 Tagaya N, Yamazaki R, Nakagawa A et al. Intraoperative identification of sentinel lymph nodes by near infra-red fluorescence imaging in patients with breast cancer. Am J Surg 2008; 195: 850-853

23 Hünerbein M. Expert report on Indocyanine green (ICG) application for sentinel node detection by fluorescence. 2009. Mitteilung der Fa. Pulsion

24 Kitai T, Inomoto T, Miwa $\mathrm{M}$ et al. Fluorescence navigation with indocyanine green for detecting sentinel lymph nodes in breast cancer. Breast Cancer 2005; 12: 211-215

25 Murawa D, Hirche C, Dresel S et al. Sentinel lymph node biopsy in breast cancer guided by indocyanine green fluorescence. Br J Surg 2009; 11: 1289-1294

26 Aoyama K, Kamio T, Ohchi T et al. Sentinel lymph node biopsy for breast cancer patients using fluorescence navigation with indocyanine green. World J Surg Oncol 2011; 9: 157

27 Cody HS 3rd, Fey J, Akhurst T et al. Complementarity of blue dye and isotope in sentinel node localization for breast cancer: univariate and multivariate analysis of 966 procedures. Ann Surg Oncol 2001; 8: 1319

28 Hirche C, Mohr Z et al. High rate of solitary sentinel node metastases identification by fluorescence-guided lymphatic imaging in breast cancer. J Surg Oncol 2011; 105: e162-e166

29 Hojo T, Nagao T, Kikuyama $M$ et al. Evaluation of sentinel node biopsy by combined fluorescent and dye method and lymph flow for breast cancer. Breast 2010; 210-213

30 Ballardini B, Santoro L, Sangalli C et al. The indocyanine green method is equivalent to the ${ }^{99} \mathrm{mTc}$-labeled radiotracer method for identifying the sentinel node in breast cancer: a concordance and validation study. Eur J Surg Oncol 2013; 39: 1332-1336

31 Polom K, Murawa D, Nowaczyk P et al. Breast cancer sentinel lymph node mapping using near infrared guided indocyanine green and indocyanine green-human serum albumin in comparison with gamma emitting radioactive colloid tracer. Eur J Surg Oncol 2012; 38: 137-142

32 Takeuchi M, Sugie T, Abdelazeem K et al. Lymphatic mapping with fluorescence navigation using indocyanine green and axillary surgery in patients with primary breast cancer. Breast J 2012; 18: 535-541

33 Wishart GC, Loh SW, Jones L et al. A feasibility study (ICG-10) of indocyanine green (ICG) fluorescence mapping for sentinels lymph node detection in early breast cancer. Eur J Surg Oncol 2012; 38: 651-656

34 Mieog JS, Troyan SL, Hutterman M et al. Toward optimization of imaging system and lymphatic tracer for near-infrared fluorescent sentinel lymph node mapping in breast cancer. Ann Surg Oncol 2011; 18: 2483-2491

35 Solomayer EF, Rody A, Wallwiener D et al. Assessment of university gynaecology clinics based on quality reports. Geburtsh Frauenheilk 2013; 73: 705-712 